\title{
Methodical approaches for creation of intelligent management information systems by means of energy resources of technical facilities
}

\author{
Ravil Safiullin ${ }^{1, *}$, Aleksandr Marusin², Ruslan Safiullin ${ }^{1}$ and Timur Ablyazov ${ }^{1}$ \\ ${ }^{1}$ Saint Petersburg State University of Architecture and Civil Engineering, Saint Petersburg, Russia \\ ${ }^{2}$ Peoples Friendship University of Russia (RUDN University) Miklukho-Maklaya str. 6, Moscow, Russia, 117198
}

\begin{abstract}
As part of the development of the digital economy both abroad and in the Russian Federation, the management of energy resources based on the use of digital technologies is one of the key tasks in improving infrastructure in order to ensure the efficient functioning of technical facilities providing the operation of capital construction projects. Currently, the spread of information and communication technologies is the basis for the development of intelligent management information systems for energy resources, which requires further theoretical and practical studies and the development of conceptually new methodological approaches to the formation of these systems. As a result of the study, the authors have identified problems in the Russian energy sector and defined methodological approaches to improving energy management systems in the functioning of intelligent buildings and structures. The result of the study is an algorithm for creation of a server center for energy consumption reduction during the operation of utilities and electrical equipment of intelligent buildings and structures, real-time monitoring of energy consumers and forecasting the energy consumption of intelligent structures and buildings (ISB), which will provide for accumulation of data necessary for optimal energy planning and will improve the soundness of management decisions.
\end{abstract}

\section{Introduction}

Power consumption is constantly increasing due to population growth and urbanization, and although the energy needs of buildings and structures depend on the climate, dwelling type and the region development level [1], 38\% of the energy consumed in the world annually is spent for capital construction projects [2]. Currently as part of the development of the digital economy both in Russia and abroad, the practice of information and communication technologies application is becoming widespread in various fields of activity, since the digital technologies are the basis for the effective interaction of various information structures and systems [3], including within the framework of technical facilities.

The concept of the "smart city" which is being spreading now is also largely based on improving the infrastructure [4], therefore, the development of methodological approaches to the formation of intelligent management information systems by the energy resources of technical facilities is one of the trends of the urban environment development.

Both federal and regional target programs for modernization of energy system in the framework of the program "Saint Petersburg - Smart City" have become the basis of the current theoretical studies for energy costs reduction during the operation of utilities and electrical equipment of intelligent buildings and structures, and as a result, reduction of the negative impact on the environment in conditions of rapidly changing quantitative and structural parameters of intelligent technical equipment with limited urban changes in historically developed target-generating zones [5].

\section{Methods}

The implementation of the "smart city" concept, which includes the energy systems modernization, is based on a clear strategy for measures performance and urban systems adaptability, since the implementation of digital technologies shall be carried out comprehensively to improve the urban environment in the field of increase in its security and efficient functioning [6, 7]. Moreover, the improvement of energy systems is one of the tools for living environment modernization, for example, during the renovation of territories, therefore it is important to introduce technical standards for functioning of these systems using BIM technologies, which are globally recognized trends of the investment and construction sphere development [8].

Building automation in the world has reached a high level; this trend is also gaining more momentum in Russia. In the market of "smart house" systems, there is a various number of proposals that differ from each other

* Corresponding author: safravi@mail.ru 
in their functionality, data transfer medium, structure complexity, etc. The relevance of the topic discussed is due to the fact that the use of automation systems that effectively control the buildings utilities is in demand both during restoration of existing electrical installations and during the design of new ones. Effective management of such building systems as lighting, heating and air conditioning can reduce energy costs, and also promotes the comfort increase during prolonged person stay in a room.

Nevertheless, the lack of uniform requirements and standards for the tools used and for the creation of automatic systems leads to confusion in concepts and appearance of equipment, including undependable software and functionality. The methodological bases and proposals for the rational use and improvement of intelligent technical means for the effective management of energy resources were developed based on the study [9]. These recommendations contain the developed methods, algorithms for selection and rational functioning of intelligent technical means, provide for the specific measures for their improvement. The tasks of the Federal and regional target programs have set the objective necessity for scientific justification and creation of the methodology of innovative technical and process solutions to reduce energy costs during the operation of utilities and electrical equipment of intelligent buildings and structures in the current conditions of changes in its quantitative, qualitative, and structural parameters in large cities. The main objectives of the programs: improvement of the balance, efficiency of energy resources management during operation of intelligent buildings and structures as part of the energy system that ensures the national interests of the country [10].

The implementation of this policy shall allow for 30$35 \%$ reduction in energy consumption during the energy system operation [11]. The programs implementation made it possible to carry out institutional transformations, further development of production of high-tech components and materials, to introduce state standards meeting the international requirements, and ensure the improvement of scientific-technical and personnel potential.

The practice of long-term programs for reduction of energy costs of buildings and structures developed in recent years in the United States and in European countries considers not only the development of expensive infrastructure, but also measures to form control of the oriented behavior of participants in the program implementation process. The experience of European cities shows that technical solutions aimed at reduction of energy costs of buildings and structures will be significantly limited in the near future. These circumstances create an objective necessity for the integration of oriented technologies to reduce energy consumption in the management of energy networks of buildings based on a system-targeted approach to the process. The basis of this approach is the provision on the interconnection of the work of intelligent technical means and the energy saving generated during its operation (in the general formulation) and, therefore, the possibility for joint optimization of these processes.

\section{Results and discussion}

The models linking the work of intelligent tools (Ptr) and the amount of energy costs $(\mathrm{Re})$ make up the regulatory and target basis for alternative implementations of scenarios for their improvement. The optimization criteria are based on combined technical and energy indicators of this process. In the process of energy management of intelligent buildings and structures, three hierarchical process levels can be distinguished: at the regional mega-level, at the local macro-level, and at the individual micro level (Fig. 1).

At each level, the energy resource management process is optimized according to the following criteria:

The size of automation systems that make it possible to effectively manage the buildings utilities in the n-th period shall not contradict with the remaining tendency of energy consumption increase in the subsequent $\mathrm{n}+1$ period $P_{\operatorname{tr}(n+1)}>P_{\operatorname{tr}(n)}\left(P_{\operatorname{tr}(n)}\right.$ is not equal to 0$)$;

the amount of energy costs (Re), Re $<\operatorname{Red}=f\left(c_{r}\right)$ shall not be greater than the amount that can be created, not exceeding the permissible values.

There are also general restrictions for levels: $A_{2 i} \in A_{3 i}$ and $L_{1 k} \in L_{2 k}$.

Optimization models are as follows:

Level 3:

$$
\begin{aligned}
& P_{3}=\sum f\left(A_{31} A_{32}, \ldots A_{3 n} ; W_{31}, W_{32}, \ldots W_{3 n}\right) ; \\
& R_{3}=\sum f\left(A_{31} A_{32}, \ldots A_{3 n} ; r_{31}, r_{32}, \ldots r_{3 n}\right),
\end{aligned}
$$

where $A_{3 i}$, is a number of intelligent building systems (IBS) $i$-x; $W_{3 i}$ and $r_{3 i}$ - respectively, the amount of automation and the size of cost reduction of one unit $i-x$ for a calendar period.

Level 2:

$$
\begin{aligned}
& P 2=\sum f(q 21, q 22, \ldots q 2 n ; A 21, A 22, \ldots A 2 n) \\
& R 2=\sum f(g 21, g 22, \ldots g 2 n ; N 21, N 22, \ldots N 2 n),
\end{aligned}
$$

where $q_{2 i}$ and $g_{2 i}$ - respectively are the amount of automation and the size of cost reduction due to function of one unit $i$-x IBS k, $A_{2 i}$ and $N_{2 i}$, - a number of $i$-x IBS;

Level 1:

$$
\begin{aligned}
& P 1=\sum f(\omega 11, \omega 12, \ldots \omega 1 n ; t o p 11, t o p 12, \ldots \text { top } 1 n) \\
& R 1=\sum f[T 2 g 1,+g 1 t(t p 11, t o p 12, \ldots \text { top } 1 n)],
\end{aligned}
$$

where $g_{1 L}$ and $g_{1 t}$ - the amount of cost reduction due to function of one unit $i$-x IBS; $\omega_{11}$ and $t_{o p 11}$ - hourly efficiency and operation time $i$-x IBS managed by the operator.

The IBS size and composition is optimized at the level 3. The IBS structure shall comply with the conditions $\left(\mathrm{C}<\mathrm{C}_{\mathrm{d}}\right)$. The modeling is carried out both for separate buildings and structures, as well as residential areas, micro-districts, with varying ratio of the IBS number, corresponding to the standards. 


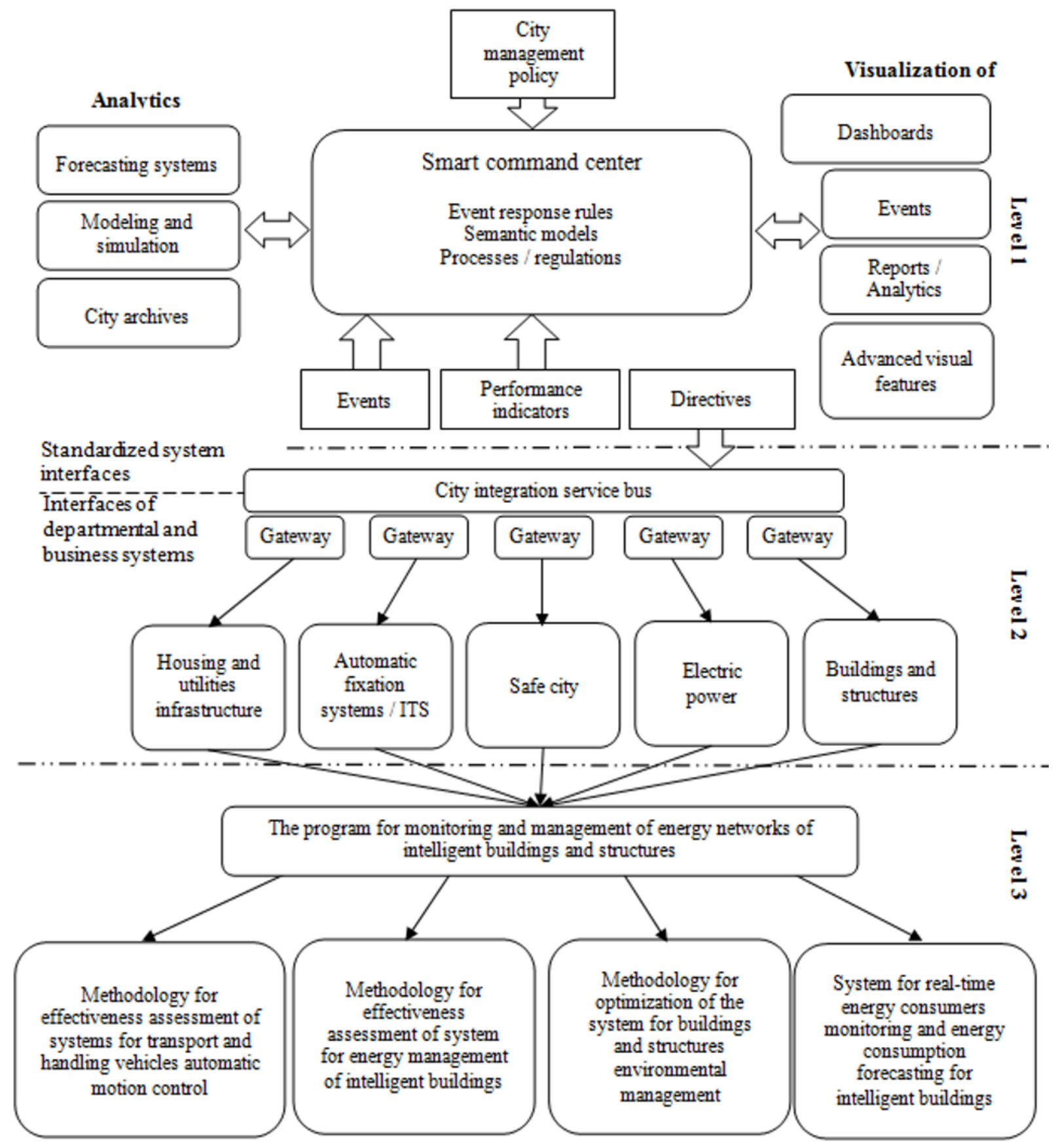

Fig. 1. Hierarchical levels of energy management of intelligent buildings and structures.

The operating mode of a separate building is optimized at level 1. IBS selection according to these criteria allows performing optimal operation with a minimum of modes not determined by the energy saving process.

In the process of the study $[12,13]$ of the energy management systems of intelligent buildings and structures, the methods were developed (Fig. 1) to increase the efficiency of energy management at each level according to the criteria for energy costs reduction during the operation of utilities and electrical equipment of intelligent buildings and facilities. The multi criteria approach was applied to assess the effectiveness of functioning of intelligent technical facilities of buildings and structures. To solve it, a technique was used that provides for ranking of all the criteria presented. In the formulation under consideration, the importance of each optimization task shall be determined by a degree of its influence on energy consumption and be evaluated by an objective indicator - the influence rank of the j-th private optimization trend relative to the most priority option $\left(C_{1}\right)-R_{S j / C_{1}}$.

Then the efficiency of optimization resource application (no worse than the accepted one) and the aesthetic (compliance of the facilities with the effective standards) expediency can be estimated by the following dependence: 


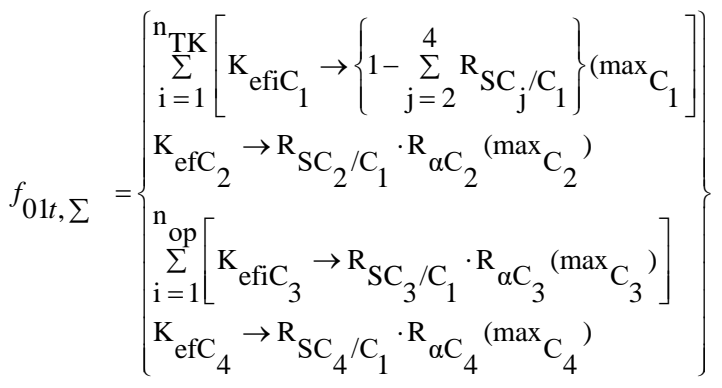

Here, $n_{T K}, n_{\text {on }}$, respectively, is a number of channels for communication with functional objects and operators; $R_{a C 1}$ - an indicator characterizing the efficiency of optimization resource application in the i-th trend.

In case of complex solution of the problem for energy consumption costs reduction during the operation of utilities and electrical equipment of intelligent buildings and structures based on the construction of three-level optimization models, a unified database is required, which is formed in the concepts of the subject area at all levels of the energy management process, providing a systematic analysis of the energy network situation development - server center for energy costs reduction during the operation of utilities and electrical equipment of intelligent buildings and structures, monitoring of IBS process application.

To reduce energy consumption during the operation of utilities and electrical equipment of intelligent buildings and structures, it was proposed to create a single database as part of the information automated system (IAS) - a server center for energy consumption reduction, real time monitoring of energy consumers during the operation of utilities and electrical equipment of intelligent buildings and structures, and forecasting of IBS power consumption (SCECR for IBS MPC), (Fig. 2). The SCECR for IBS MPC should provide the possibility to collect combined information, its formation

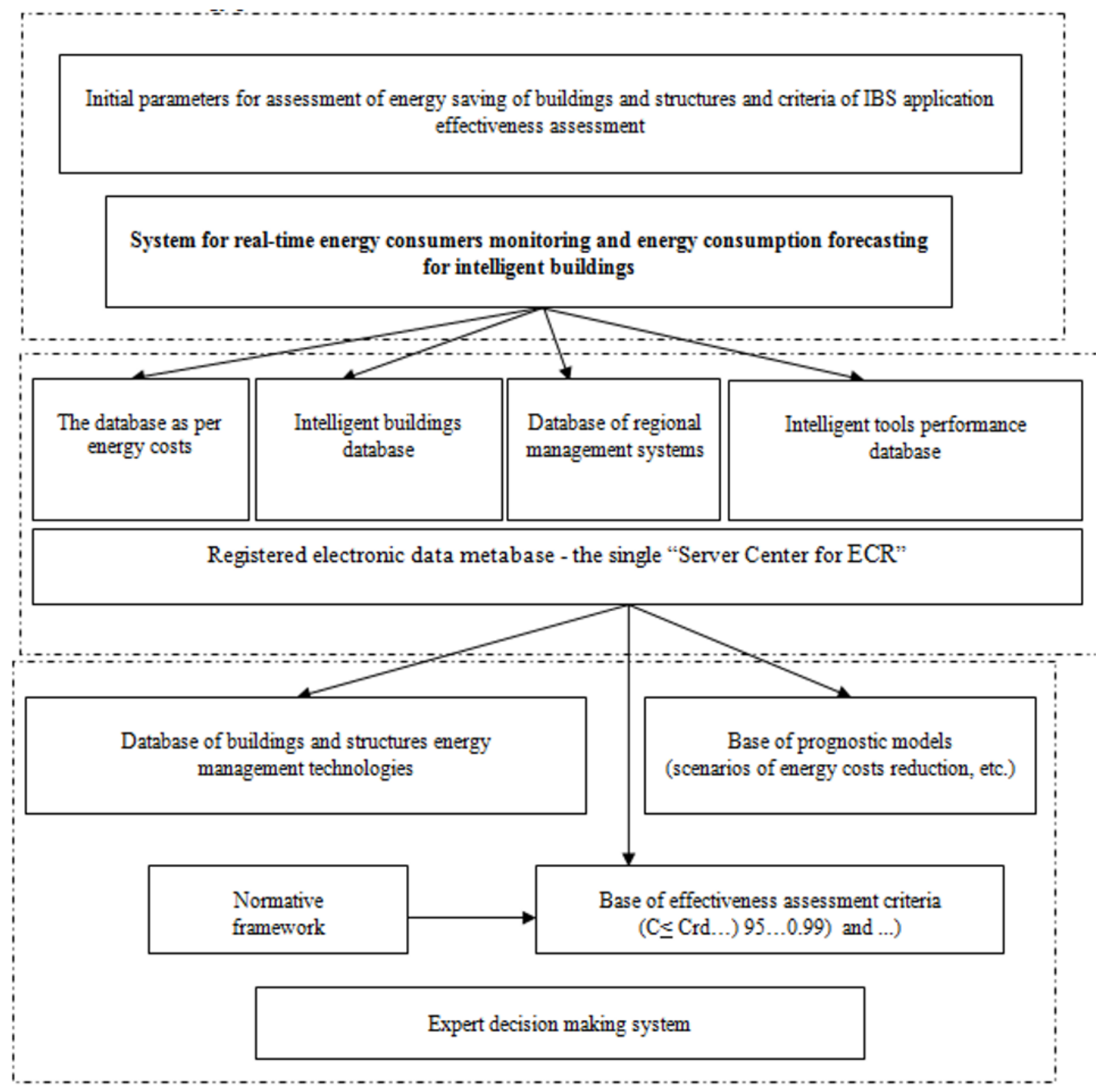

Fig. 2. Structural and functional diagram of the automated information data base of SC ECR. 
in terms of a subject area of 3 levels of the energy resource management process and systematic analysis of costs and energy saving situation in the region. Information collection for the SCECR as a component of the intelligent buildings and structures system can be carried out according to the data of periodic checks of the IBS technical condition, with permission to install, according to the results of operational monitoring of energy saving status by mobile laboratories, and control of GLONASS/GPS system as per the navigation information. To receive, archive information and model scenarios for the development of energy-saving situations, the GIS technology products can be used.

\section{Conclusion}

Energy management issues are one of the key issues within the framework of digital technologies spreading, since the energy sector combines various activities and directly affects the population life quality. Using the digital transformation of energy consumption, it is possible to achieve an intelligent response to demand, to create systems for integration of various energy sources, and to promote the spreading of renewable energy sources [14]. Improvement of intelligent energy resource management systems will allow developing the optimized decentralized solutions based on the interaction of various elements of the energy system, combining the capabilities of all available energy sources [15].

The formation of intelligent management information systems in the energy sector contributes to their further integration into digital platforms, which are a driving force for socio-economic development, simplifying the interaction of suppliers and consumers [16]. According to the experts' outlook, the annual expenses on the digital transformation of the electric power industry will globally increase to $\$ 3.8$ bln. by 2020 [17]. The methodological approaches proposed by the authors for the formation of intelligent management information systems by the energy resources of technical facilities can also be integrated into digital ecosystems based on the Internet of things technology [18].

As a result of the study $[11,19,20]$ the methodological approaches to improve the system of energy monitoring and management in the functioning of intelligent buildings and structures are determined. The proposed server center for energy consumption reduction during the operation of utilities and electrical equipment of intelligent buildings and structures, real-time monitoring of energy consumers and forecasting the energy consumption of intelligent structures and buildings will provide for accumulation of data, which is urgently necessary for implementation of many types for energy saving planning, and can improve the soundness of management decisions, as well as will promote to predict the effect of introducing the oriented technologies into the process of effective energy management.
The article was prepared as part of the work on the grant of the President of the Russian Federation NSh4028.2018.6.

\section{References}

1. Inter Academy Council Lighting the Way: Toward a Sustainable Energy Future 2007. http://www.interacademycouncil.net/File.aspx?id=2 $\underline{4548}$

2. Izzet Yüksek, Tülay Tikansak Karadayi, EnergyEfficient Building Design in the Context of Building Life Cycle (IntechOpen, London, 2017)

3. T. Ablyazov, V. Asaul, SHS Web of Conferences 44, 00003 (2018)

4. A. Vishnivetskaya, E. Alexandrova, IOP Conference Series: Material Science and Engineering 497 (2019)

5. V. Vasiliev, 2018. Smart Saint Petersburg: concept of Saint Petersburg development with the "smart city" technology .

https://docs.wixstatic.com/ugd/548461_be60daeea6c a4768944e3af8344ba8b5.pdf

6. R. Giffinger, H. Gudrun, 2010. Smart cities ranking: An effective instrument for the positioning of the cities ACE: Architecture, City and Environment. https://core.ac.uk/download/pdf/41793309.pdf

7. Toppeta D., 2010. The Smart City Vision: How Innovation and ICT Can Build Smart, "Livable”, Sustainable Cities. https://intaaivn.org/images/cc/Urbanism/background\%20docu ments/Toppeta_Report_005_2010.pdf

8. A. Vishnivetskaya, A. Mikhailova, IOP Conference Series: Material Science and Engineering 497 (2019)

9. R. N. Safiullin, A. S. Afanasyev, V. V.Rezchenko, Journal of Mining Institute 237 (2019)

10. A. A. Kondratiev, International Transport Academy 17 (2014)

11. Tariff committee 2019 Electricity rate in Saint Petersburg.

https://www.pes.spb.ru/for_customers/electricity tar iffs/electricity tariffs_for_st_petersburg/

12. R. N. Safiullin, M. A.Kerimov, Means of photo and video recording of traffic offenses: control and practice (Direct Media, Moscow, 2016)

13. R. N. Safiullin, M. A. Kerimov Intelligent on-board transport systems in road transport (Direct Media, M.-Berlin, 2017)

14. IEA 2017 Digitalization and Energy. https://www.iea.org/digital/

15. P. Vingerhoets, M. Chebbo, N. Hatziargyriou, The Digital Energy System 4.0, 2016. https://www.etipsnet.eu/wp-content/uploads/2017/04/ETP-SGDigital-Energy-System-4.0-2016.pdf 
16. T. Ablyazov V. Rapgof, IOP Conference Series: Material Science and Engineering 497012002 (2019)

17. DNV GL Energy Digital Transformation of Energy Systems, 2017. https://www.dnvgl.com/publications/digitaltransformation-of-energy-systems-103321

18. S. Gong, Y. Wang, M.Zhang, MATEC Web of Conferences 139 (2017)

19. L. N. Kozlov, Yu. M. Urlichich, B. E.Tsyklis, Transport of the Russian Federation 3-4 (22-23) (2009)

20. Safiullin R.N. Useful model patent No. 174174 RF. Automated system for data monitoring of vehicle internal combustion engine technical condition. Published on 05.10.2011. Bulletin No. 28 